\title{
Playful Probing: Making Probing More Fun
}

\author{
Regina Bernhaupt, Astrid Weiss, Marianna Obrist, and Manfred Tscheligi \\ HCI \& Usability Unit, ICT\&S Center, University of Salzburg \\ firstname. lastnamedsbg.ac.at
}

\begin{abstract}
We present a methodological variation of cultural probing called playful probing. In playful probing games are developed according to the area investigated, to enhance participants' involvement in the studies. The games are used as additional probing material and enhance participants' involvement. Based on an experimental case study with 40 households participating in a ethnographic study on new forms of media usage in the home context we show how playful probing can successful support users' engagement during the ethnographic study. We found interesting insights, for example the amount of data provided on creative cards doubled for households using the playful probing approach compared to households not using playful probing. Thus the methodological extension seems worth the effort when used in ethnographic studies within the home context.
\end{abstract}

Keywords: Ethnography, cultural probes, playful, method, computer technology usage in households, interactive TV.

\section{Introduction}

Today there is a steady growth of technology usage in the context of peoples' homes. To address the need for understanding technology usage in everyday life, various methods have been used. In the field of human-computer interaction ethnographic methods are used to better understand how technology is adopted and used in the home context. In the Casablanca project, for instance, Hindus et al [14] investigated how media space concepts could be incorporated into households and family life. They used ethnographically inspired field studies and in-depth interviews to evaluate early prototypes for home communication in real world settings. Taylor \& Swan [26] or Crabtree \& Rodden [8], among many others, used ethnographic methods and variations focusing on domestic routines and the role of technology in home life. All these ethnographically inspired studies have in common, that they involve researchers as integral part of the field study. To limit the effects of researchers taking part in the field studies, new methods (like cultural probing) are used enabling the investigation of daily life without researchers' participation.

Cultural probes were invented to provoke inspirational responses from participants [11]. This method uses a package of materials, for example post-cards, maps, photo albums or media diaries. Participants use the material to describe their everyday experiences and to answer questions in an informal way. Cultural probing turned out to be a valuable method to gather rich in depth qualitative data about the private life 
of the participants to inform design of technology (like computers). Meanwhile several variations of cultural probing were developed like empathy probes [19], technology probes [17] or mobile probes [15]. Moreover, Crabtree et al. [7] adopted cultural probes for the care sector in order to better inform the design of applications for this sensitive environment, and Iversen \& Nielsen [18] further developed cultural probes for the use with children.

Depending on the material used for the cultural probes method, results and return rates can vary extremely. To improve cultural probing we wanted to intensify participants' involvement in the study and enable children's participation. We wanted participants to have more fun when taking part in the study. Thus we developed a new methodological approach called playful probing.

In the following we present playful probing, a methodological variation supporting active participation by using games as integral research tool. We present the concept "playful" as an advanced way to involve users in the data collection process and demonstrate the development and usage of playful probing and show in an experimental case study how this methodological variation increased users' participation, especially the involvement of children.

\section{Related Work: The Concept of "Playful" and Cultural Probes}

Children Research Net (CNR) [9] defines playful as "a certain feeling or emotion, the thoughts, curiosity and inquiring mind that arise when an individual is absorbed in something. The definition of 'playful spirit' also includes sympathy for others, positive attitudes, and a concern for people and things. In other words, a playful spirit encourages children's spontaneous learning". The CRN stresses that playfulness enhances children to fully use the capabilities of mind and body, and that general a person being absorbed in play is filled with excitement and 'joie de vivre' enabling mind and body to work intensively.

Using games to make experiences more enjoyable was addressed in various disciplines. Especially in the area of (e-)learning the concept of play was used. For instance Egloff [10] conducted a case study on interactive CD-ROM play-sets where correlations between gender, age and knowledge regarding edutainment were investigated.

Overall, games and gaming can be seen as an adequate methodological extension to conventional methods in order to increase children's participation in research and in the design process. However, games can also help to increase participant's motivation to take part in the study. Muller et al. [22] summarized the benefits of gaming as research technique as follows: Enhanced communication, enhanced teamwork, improved articulation of the perspectives, knowledge, and requirements, and new insights leading to important new analyses and designs. Based on this advantages Muller [21] developed several games for the practice of participatory design, like CARD, a card game for visualising work activity flows, PICITVE, a paper - and - pencil game for screen design, Icon Design Game for generating new ideas for icons, and Interface Theatre for design reviews. 
A growing amount of literature has emerged discussing the involvement of children in the research process of human-computer interaction. Different methods were already used to integrate children into the design process. For instance Burov [4] used observations with videotaping to discover activity patterns in children's' play and used additionally standardised questionnaires. Candy and Edmonds [5] conducted a study concerning on the computer usage to support the learning process of children with particular basic language difficulties. The dialogues between the students and the computer were recorded and discussed afterwards. Others showed patterns of children's interactions with different system tools by capturing logging data [23], or conducted observations of children's reactions to HyperCard menus and commands and tracked their navigation patterns [24]. Wyeth [27] conducted an ethnographic study on children's play experiences in a Kindergarten. The study focused on how new playful technology for young children needs to be designed. To better address children's' needs Read [25] developed special questionnaire instruments called "funometer" and "smileometer" measuring the satisfaction rate of children.

To add a 'playful' component in a methodological approach seems to be a reasonable step to enhance participation and to increase involvement of children in research studies.

Cultural probing is a method developed in the tradition of artists and designers rather than being based on the more typical engineering approaches. Developed by Gaver et al. [11], the cultural probes approach plays an important role in the initial phase of a user-centered design process. Cultural probes are purposefully designed to inspire, reveal and capture the forces that shape an individual and his/her life, at home, at work or on the move [13]. It is a method for understanding participant's behavior and experiences in situ. Probes are mainly used to gather insights on the users' context in order to better inform the design process in an early stage [11], [19]. Cultural probing differs from traditional field and ethnographic methods, like observation and interview, as the researcher is remote from the participants. The participant is the observer him/herself.

When conducting a study using cultural probing a so called probe packages is provided to the study participants. The probe package normally consists of diaries, cameras, post cards, sometimes maps of the explored environments, and several other means to obtain as much data as possible from the participants. Participants are free to control time and means of capture. Gaver et al. [11] reported that return rates of materials can vary significantly in different settings and populations.

Apart from the traditional cultural probe approach new methodological variations have been developed, like domestic, technology or mobile probes ([17], [7], [1], [15]). Mobile probes are mainly used to explore the mobile environment in order to explore people's activities in mobile contexts, but it is not a usability evaluation method. Technology probes involve installing a technology into a real use context, watching how it is used over a period of time, and then reflecting on this use to gather information about the users and inspire ideas for new technologies [17]. Especially in the ethnographic study of Battarbee et al. [2] it was tried to address children with cultural probes. Animal stickers were used which should be assigned to the different technologies in the children's surrounding. The presumption therefore was that children imagine electronic devices as „sort of alive“ and that animal metaphors can give a deeper insight on how children experience technology. However, the study 
revealed that the abstraction level with the stickers was quite difficult for children. Iverson et al. [18] used digital cultural probes for addressing children's everyday live. Therefore children were asked to send audio-visual material by a mobile phone to a web-page to investigate what is interesting, funny or relevant for them. The produced content could be shared by the children as well as by the researchers.

Cultural probes can inspire design by providing a range of material reflecting important aspects of the participant's context of use and potential usability factors. In the initial setting results were used to inspire the design of new technology. Other studies used the gathered material to inform design in a more structured way, for example by developing scenarios and personas based on the findings.

\section{The Method: Playful Probing}

Playful probing is a new variation of the cultural probing method. It uses the standard set-up of cultural probing, taking for example post-cards or post-its as probing material to gather insights on people's habits and usage. The playful probing approach differs from the traditional approach as it uses games that are specially designed for the study. In playful probing the games are designed focusing on the research area addressed within the study. The development for the game itself depends on the study set-up. Depending on the topic to be investigated, variations of existing games can be used or even new games are developed.

Within playful probing, games are used to evoke users' insights on the areas and themes explored within the study. As a major advantage we expected that users will focus on the areas explored, while using the games and gain new insights. Based on these insights other probing material is used and answered in more detail. Additionally games could help to better involve children in the ongoing study.

Using the method of playful probing is challenging Based on the area to be investigated a game has to be designed. First, the game should include the topic of research. The developed game also has to fulfil all expected characteristics of a game [20]: fun while playing the game, clear goals and rules, defined beginning and end. To facilitate the development of the games we started with existing and frequently used games.

We developed several variations of traditional card playing games. Variation one was a card playing game called "Neunerln". We extended the normal card game by additionally printing questions on the cards. The goal of the game is to get rid of all the cards as soon as possible. Cards have four kinds of symbols (colours) and numbers on them. In the beginning one card is in the middle (visible) and the first player can lay down a card either if one card has the same symbol or the same number. The player wins, if he is the first one to have no cards left. To reduce the number of negative points in the case of loosing, the player could answer a question card on the game. We used this game in an ethnographic study in May/June 2006 investigating users' experiences with interactive TV during a local field trial. Based on our first experience with playful probing, we recognized that the more professional the cards look like, the more the participants were motivated to use the game. Moreover, it became clear that changing original rules in the game made it more difficult to play. Participants neglected to use the changed rules, as they were used to play the game with the original rules and it was difficult to remember the changed rules. 
A second variation was the development of a game using small cards with verbs and adjectives on them. The goal of the game was to describe objects using verbs and adjectives on the cards. We started to use technology-oriented objects. The goal of the game was to describe the object with the verbs and adjectives on the cards. We used this game in internal trials and found out, that the number of verbs and adjectives available was too large, rules were too complicated, and production costs too high to be effectively used.

When using playful probing, the adoption of an existing game without replacing the rules of the game is important. On one hand, it is the easiest and cheapest way to develop the needed material. On the other hand, it doesn't require the participant to get used to the game, thus increases the potential of usage. These insights and lessons learned from the two trials built the basis for development of a novel playful probing design which will be described in the following chapter.

\section{The Experimental Case Study}

Based on former experiences with playful probing and the development of variations of several games, we conducted an ethnographic study using playful probing in September 2006. Main goal was to evaluate if playful probing improves the "traditional" methodological set-up of cultural probes. The study focussed on TV and media consumption habits and the use of remote controls. Results from that study can be found in [3].

For the material we developed a basic probe package consisting of specially designed creative cards including modelling clay, post-its, and sweets which all participating households received. We called this special collection of material creative cultural probing. Usage and development of creative cultural probing is described in [3]. The methodological impact of this kind of material is still the focus of a long-term investigation and will be described elsewhere. Additionally we developed a playful probe package for selected households consisting of a game based on two frequently used games in Austria and Germany. The development and usage of the games are described in the following.

\subsection{Developing the Game}

To be able to profit from the moment of playfulness we combined the card-game UNO with some additional question cards following the standard rules of the game. We chose this well known card game as basis, because it is easy to play for children, but also addresses adults. We knew from experience, that the game is easy to learn, as it follows easy rules.

Each player receives seven cards. The remaining cards are placed face down to form a drawing pile. The top card of the drawing pile is turned over and acts as discard pile. The first player has to match the card in the discard pile either by number, colour or word. If the player can not use one of his cards, he has to take one card from the drawing pile. If the drawn card fits he can play, otherwise it's the next person's turn. UNO got his name from the rule that in case a player has only one card left, he has to say UNO. Failing to do so, results in taking again two cards from the 
pile. The goal of the game is to get rid of all the cards as fast as possible. The first one without any cards is the winner. The other ones have to count (negative) points, based on the remaining cards in their hands (see Figure 1).

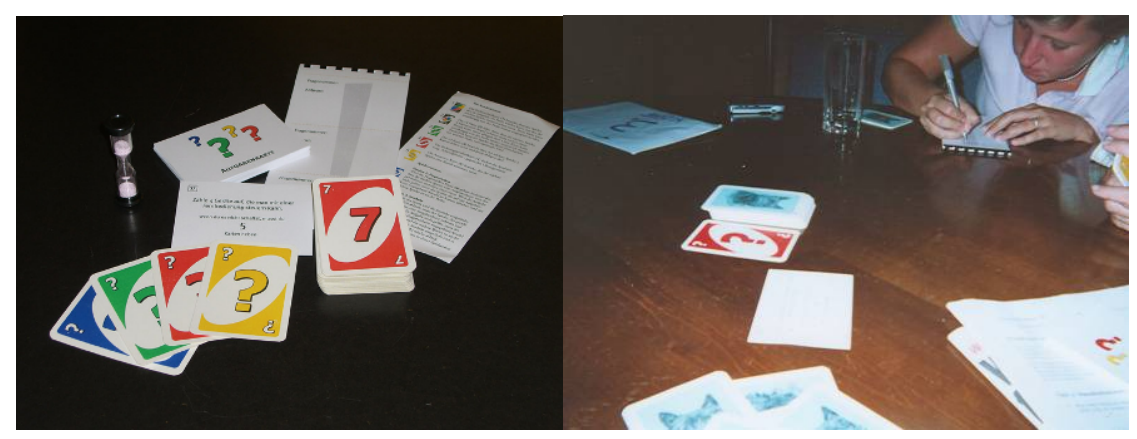

Fig. 1. The playful probing package (left) and a family playing the game developed for the study (right). All photos used with permission of the participants.

We rebuilt the cards and extended the gaming rules by using concepts from a game called "Activity". As we learned in previous studies, that changing the rules might be too difficult for people to follow, we simply added some features according to the rules. We introduced a new card showing a question mark. If the "question mark" card was used, the following player had to draw a card from an additional card pile and had to fulfil the given task. To relate the game to the research area, we used so called "activity" tasks. We included various kinds of activity tasks to address different skills and to make the game more diversified. Examples for the tasks are for instance: "Think of a technology and describe it with the words: unaffordable, open, vitaminpacked, simple, and professional. Let the others guess". "Pantomime: Imitate the Internet and let the others guess.", "Draw a combination of a remote control and a mobile phone. Let the others guess which two devices you have drawn." If the other players could not guess the right answer it was a failure and they had to take cards from the regular drawing pile as penalty. The activity tasks were inspired by a common game in Europe called "Activity". The activity tasks consisted of 48 cards which were addressed to the three research areas we wanted to investigate. Additionally all participants were asked to write down their answers on a notepad so the data could be used as probing material.

A further variation - especially created for adults - was the usage of sand glasses with 30 seconds duration instead of the "question mark" cards. Whenever the sand glass finished, the one currently laying down a card, has to answer an activity task. This variation made the game flow quicker. Participants reported increased fun, when playing this variation among adults.

The main advantage of this game is that it is reusable for different research areas by simply changing the questions or activity tasks. We currently explore other games to be used as an additional instrument for data collection considering factors like ease of use and cheap production within a reasonable time frame. 


\subsection{Study Set-Up}

Our ethnographic study focused on how technology is used in everyday life. We focused on new forms of media usage in the home, to explore possible new concepts of interactive TV navigation and remote control development. To thoroughly explore the different aspects of technology in the households we used creative cultural probing with the above described materials for all households and playful probing for selected households. The playful probe package consisted of the developed game (see Figure 1).

To evaluate the playful cultural probes method, 40 households were recruited. 20 households being media-entertainment oriented (means above-average equipped with and interested in entertainment technology), 20 households representative for the population of Austria (concerning media usage, household size and income). We balanced the number of household members in the two groups, choosing 14 households with three or more family members and six households with couples. 20 households were equipped with a multi-functional video camera (Mustek DV5200 or Mustek DV9300), all other households used a one way disposable camera. We had requested the participants to take a photo each time there was a symbol on the creative cultural probing card or they are on the road and in contact with technology (the importance of this was made clear to participants as it was necessary to obtain more information for the extended home concept).

All households received a package with creative cards and some modeling clay. The creative cultural probing cards are designed following a special topic for each week within the ethnographic studies, like "When I am on the move". We investigated three concepts: extended home, shared experiences and new forms of interaction techniques with a special focus on remote controls. Additionally the playful probing material was distributed counter-balanced between the two household-groups, number of household members and recording device. The study lasted three weeks, with a first introductory visit and a final in-depth interview conducted by a researcher in each participating household.

\section{Results}

Based on in-depth interviews at the end of the study and based on the quantitative demographic data collected by a questionnaire, we evaluated how the participants used the game in particular. To present the gathered data and material in a readerfriendly way, we report the main findings in two usage scenarios. These scenarios are based on the interviews and show a summary of typical usage scenarios of playful probing as reported by the participants.

Family Maier consists of four persons, Christina (42), her husband Mario (47) and the sisters Susi (6) and Nicole (10). Mario is working full time as a teacher in a secondary school while Christina is working half time as a secretary. Mario gives private lessons in his free time to improve his wage and allow his family a small amount of luxury.

Susi and Nicole enjoy their time in primary school. Even more than their time in school they love the free afternoons, when they leave the flat of the family and meet 
their friends in the shared garden. When it's raining the sisters get really nervous because they can not go into the garden so Christina tries to distract them by offering them some activity like playing a game or baking a cake. Although playing games with her mother is fun it is even better when Mario joins and the family is together.

Both parents do not watch TV very often, firstly because they don't like most of the programme and secondly because they want to give an example to their children. Therefore, Mario and Christina often try to find alternative activities for the evening, when the whole family is together. Instead of watching TV they prefer talking about the day or playing games. When the children are sleeping, Christina is doing the household, while Mario is preparing the material for the lessons for next day. That is the time of the day where the radio or the TV runs in the background.

Eva (26) and Peter (32), a young couple, are not married so far, but they life together in a small flat for two years now. Peter just finished his studies and is now working as research assistant at the university. In his spare time he loves to play on his game station or online games in the Internet. He always tries to stay informed about new technological innovations and devices, and thus he reads a lot of computer magazines. He wishes to have a better wage for buying more entertainment devices, because most of the time Eva decides that there is no money left for something new. Eva is still studying at the university. She has little leisure time because besides writing her diploma thesis she is working half time in a call centre. She is not really interested in technology and entertainment devices and wishes that Peter would spend more time in the evening with her instead sitting in front of the computer. Therefore she tries to convince Peter as often as possible to play the card game with her, as she knows that Peter really loves to put the last card on the staple in the moment the sand glass finishes. He enjoys making the game a bit more difficult for her to play, and she is happy to spend some time with him.

The usage scenarios describe the typical usage of playful probing, as reported during the final interviews from several participating households. The data (described as scenario) shows that even households without children were using the game. Reasons therefore are that the game in general is also suitable for adults and that the variation with the sand glass supports the fun experience of adults.

\subsection{Influences of Playful Probing}

The game stimulated families to play. One father stated: "The game was good, as it brought all family members at one table; it mobilizes family members to play together." (household 20, male, 42 years old)

The fact that we chose a well known game was appreciated by the participating households: "It was funny to play, because everybody knows how to play the game, also the combination of 'Activity' and 'UNO' was nice." (household 17, male, 25 years old)

One household did not play the card game at all, because of little leisure time, but the family father mentioned that the idea was excellent: "I had the game, but we never played. The idea is great, [...] but we never played, it was an unfavourable time, because other things were of more interest "(household 13, male, 40 years old).

Two more households only played a short time and later on filled in the answers on the notepad without playing. The following tables show an overview how many of the 
activity task cards were answered in the participating households (with the playful probing material).

Only one out of the 18 households ${ }^{1}$, which actually played, complained about the game and stopped playing it, because the family did not like it: „The question cards disturbed the flow of the game, we did not want to play any longer; we (our family) always played a lot [...] therefore we only played the game once, because that was not a game any longer" (household 5, female, 46 years old).

Table 1. Answering rate of the question cards $(\max \mathrm{N}=48)$

Standard households with playful Media-oriented households with playful material $(\mathrm{N}=9)$ : material $(\mathrm{N}=9)$ :

\begin{tabular}{|c|c|}
\hline household 2 & 35 \\
\hline household 3 & 20 \\
\hline household 4 & 30 \\
\hline household 5 & 40 \\
\hline household 6 & 20 \\
\hline household 7 & 48 \\
\hline household 8 & 16 \\
\hline household 9 & 16 \\
\hline household 10 & 46 \\
\hline
\end{tabular}

\begin{tabular}{|c|c|}
\hline household 11 & 45 \\
\hline household 12 & 29 \\
\hline household 13 & 9 \\
\hline household 14 & 44 \\
\hline household 15 & 34 \\
\hline household 16 & 24 \\
\hline household 17 & 46 \\
\hline household 18 & 7 \\
\hline household 19 & 36 \\
\hline
\end{tabular}

Table 1 Number of question cards answered by participants using playful probing showing that household interests and knowledge in the domain do not have an effect on playful probing.

\subsection{Results from Cultural Probing Cards}

To understand our impression from the qualitative analysis of interviews and other data, we started to investigate possible influences of the game. We do not want to analyze the material on a quantitative (statistical) level but show on a more qualitative base, how the method can help to improve the involvement of participants. We analyzed the collected material from the probe packages separately for households with and without the playful probing material. Sample 1 are households with the playful material (20 households, 74 participating household members), sample 2 are households without the playful material (again 20 households, 57 participating household members). As described before, we balanced the number of household members in the two groups, choosing 14 households with three or more family members and six households with couples for each group. We compared these samples in the amount of information given on the creative cards. As we collected all the material during the final interview we had a $100 \%$ return rate ${ }^{1}$.

\footnotetext{
${ }^{1}$ One of the 20 households, which received the playful probing material, quit the participation of the whole study (without mentioning any reasons).
} 
Three categories to quantitatively measure the amount of content were built on how detailed the cards were filled in: 1: under average (less then $70 \%$ filled in), 2: average (70-80\% filled in), 3: more than $80 \%$ filled in. Each of the 13 creative cards were assessed in amount, afterwards the categories were coded with $-1,0,1$.

The comparison showed that playful probing has an impact on the percentage of creative cards filled out: the summarized card values from the two household samples equalled 82 for sample 1 and 38 for sample 2. Standardised by participants results equalled a value of 1,2 for sample 1 and a value of 0,67 for sample two. For sample 1 (with the game) the value is doubled compared to sample 2 (no game).

In general it can be said that the households with the playful probing material produced about twice as much content on the creative cards compared to households without the game. We see our assumption confirmed, that the playful probing method involves the participants more into the topic, even though six of the participating households self-estimated in the final interview that the game did not influence their engagement with the topic.

\subsection{Results from the Photographs}

The households in the playful probing condition took 182 photos and videos for selfdocumentation. The households without the playful probing took 181 photos and videos. So it seems that the game neither increased, nor reduced the user motivation to take photos.

Worth to mention is the fact that all households who received a one way disposable camera took pictures, but 8 out of the 20 households who received a multi-functional video camera did not take any photos or videos. The reason therefore could be that parents are afraid that their children could damage the camera or that in general not media-entertainment oriented households are skeptical using a camera never used before. Probably it is more useful when working with children and not mediaentertainment oriented households to use one way disposable cameras.

Interesting is also that according to the split design regardless of the playing condition there is no clear difference between the normal and the media-oriented households. The normal households documented more by photographing (214 photos and videos) than the media-entertainment oriented households (149 photos and videos). A reason therefore could be that the media-entertainment oriented households understand more technologies as self-evident in their every day life and consider them not worth documenting, so they only photographed "uncommon" situations.

\subsection{Results from the Modelling Clay}

The 40 households invented 38 devices as response to the thematic area new interaction techniques. 17 households created their innovations with modelling clay and three households even formed more than one device. Seven households from sample 1 created their invention with modelling clay and built 10 objects. On the other hand eleven households from sample 2 built thirteen figures with modelling clay. The number of inventions did not seem to be affected by using the game or not using the game. 

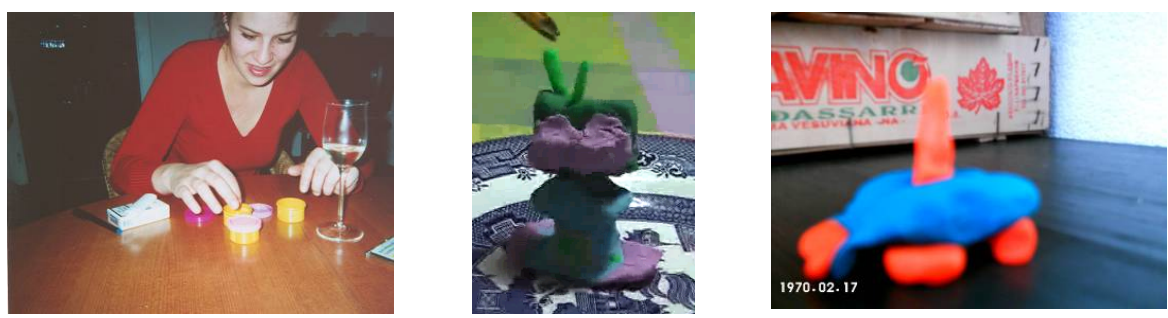

Fig. 2. User participation and creations of ideas for interaction techniques by using modeling clay. All photos used with permission of the participants.

\subsection{Results from the Post-interview}

The results from post in-depth interview were clustered into answer categories and can be summarised as follows:

18 households from sample 1 played the card game and wrote their answers on the notepad. One household even played the game while they were on holidays, all other households only played at home. In general the game was judged positively by all participants except one. Seven people mentioned that the idea was funny, two described the game as pretty nice, three answered that UNO is a card game everybody knows and which is always funny to play. Two households described the question cards as funny and two other households even wished to have more question cards.

The opinion whether the game supported the examination with the topic "household and technology" differed between the 18 households: six participants answered yes, four not really and six participants also mentioned that the game showed how many useless devices they store at home (indicating that participants gathered new insights into existing habits). Only two households mentioned that no stimulation is needed to be in touch with this topic, because it is present every day.

Nevertheless, 12 households answered in the final interview that they did not develop any new ideas for devices inspired by the game. Other households mentioned that they invented the following devices because the game inspired them: a mobile phone remote control (two times invented), a remote control that can be operated from far distances even outside the house, a remote control for the fridge and a combination between a turntable and a radio.

In general the idea of the game was appreciated by the participants. They favoured the fact that they already knew the game and did not have to learn new rules. Furthermore the game supported the participants recognizing already existing habits regarding technology, so the game seems to help revealing existing domestic routines.

\section{Advances and Shortcomings of Playful Probing}

The main advantage of playful probing is the higher user involvement during the research process. As ethnographic studies normally last over longer periods it is important to motivate the participants to be engaged with the research topic. Playful probing presents an amusing way of self-observation, which helps participants answering the probing materials faster and more efficient. Participants even engage in 
the study while playing the game. Using the game described in the case study, participants answered questions on three research areas while playing the game.

Furthermore playful probing involves children into the research project. They can prove their knowledge with the question cards and integrate their own ideas. Therefore playful probing is a way to get a deeper insight in everyday life of children and their interests in technology.

Definitely playful probing is a promising way to investigate the daily routines of families with children in the context home, above all it can reveal family habits based on the relationships of the family members. When all family members are playing together discussion and topics can arise in the family which would probably never develop without the gaming situation. For households without children it will be necessary to make the game more attractive, because adults seem to quickly loose the interest of playing if the challenge is too low.

Summarized the experimental study showed that participation of households in the playful probing sample was higher compared to households not using the playful probing approach. Playful probing has no negative effect on other probing materials, like taking photos or using the modelling clay. It is thus a useful extension of cultural probing to increase participants' motivation and children's involvement. We will further explore the concept of using games in ethnographic research. We will extend the samples to larger populations (more than the 40 participating households like in the described ethnographic study) and will use playful probing in other research areas beyond media usage in the home.

\section{Conclusion and Future Work}

Playful probing is a reasonable method to increase participant's engagement in a study using the cultural probing approach. Children can be more actively involved into the research using cultural probes. The experimental methodologically case-study showed that the answers provided by the participants doubled when in the playfulcondition compared to participants not using (having) the game. The game does not influence the number of photos or videos taken, nor does it influence the number of material used. But it helps people to focus on the investigated area. The game helps to gain new insights in a playful way (for example when answering the question: Guess how many cell phones all the people playing the game own).

Based on the experience when designing and developing the probing material we can say that playful probing is a new and innovative way to attract participants and to motivate their active participation. It also helps to include children in the research process and is a good starting point for discussion in the post in-depth interviews in order to gain more detailed user feedback on the addressed research topics. The development of the game showed, that not all kind of games might support playful probing, but the game presented in the experimental study has proven to be functional and re-usable for other research topics by simply adjusting the question and activity cards if the method of playful probing should be used.

Playful probing proofed to be a method for gathering in-depth data of participant's opinions, attitudes, and ideas in a favourable way for the participants. Based on these 
findings we will develop further variations of the method based on the feedback from the participants and preliminary lessons learned.

Concerning the game we will iterate the card game to extend different sets of activity cards for different age classes. So we can gain direct insight in the world of children and adults. Second we will enhance the concept by using more than one game to address participant's preferences in game selection. By developing more variations on the game we will also develop a set of guiding principles for playful probing game design.

From the methodological perspective we will explore possible influencing factors (especially the material developed for the creative cultural probing concept) on a long term scale. Currently we are working on a meta-review of four ethnographic studies using the playful probing and creative cultural probing method.

\section{References}

1. Arnold, M.: The Connected Home: probing the effects and affects of domesticated ICTs. In: Adrian, B (ed.) Artful Integration: Interweaving media, materials and practices, Proceedings of the Eighth Biennial Participatory Design Conference, PDC'04, Vol. 2 (2004)

2. Battarbee, K., Soronen, A., Mäyrä, F.: Living in a zoo: bringing user experiences with technology to life. In: Proceedings of the NordiCHI'04, pp. 373-376. ACM Press, New York (2004)

3. Bernhaupt, R., Obrist, M., Weiss, A., Beck, E., Tscheligi, M.: Trends in the Living Room, Interactive TV a shared experience. In: Cesar, P., Chorianopoulos, K., Jensen, J.F. (eds.) EuroITV 2007. LNCS, vol. 4471, Springer, Heidelberg (2007)

4. Burov, A.N.: Development of creative abilities of students on the basis of computer technology. In: First Moscow International HCI'91 Workshop, pp. 289-296 (1991)

5. Candy, L., Edmonds, E.A.: A study of the use of a computer as an aid to English teaching. International Journal of Man-Machine Studies 16(3), 333-339 (1982)

6. Crabtree, A.: Ethnography in participatory design. In: Proceedings of Participatory Design Conference (PDC'98), pp. 93-105. CPSR, Palo Alto, CA (1998)

7. Crabtree, A., Hemmings, T., Rodden, T., Cheverst, K., Clarke, K., Dewsbury, G., Hughes, J., Rouncefield, M.: Designing with care: adapting Cultural Probes to Inform Design in Sensitive Settings. In: Proceedings of OzCHI2003: New Directions in Interaction, Information Environments, Media and Technology (2003)

8. Crabtree, A., Rodden, T.: Domestic Routines and Design for the Home. CSCW: The Journal of Collaborative Computing 13(2), 191-220 (2004)

9. CNR - online

10. Egloff, T.H.: Edutainment: A Case Study of Interactive CD-ROM Playsets. In: Computers in entertainment, ACM Press, New York (2004)

11. Gaver, B., Dunne, T., Pacenti, E.: Design: Cultural Probes. Interactions 6(1), 21-29 (1999)

12. Goldin, R., Bell, N.: Ethno-Design research: Making a space for the user in the future of media devices. Workshop Position Paper for CHI 2006, April 22-27, Montreal, Canada (2004), available at: http://soc.kuleuven.be/com/mediac/chi2006workshop/files/ethnodesign_research.pdf (last visited 31-01-2007)

13. Hemming, T., Crabtree, A., Rodden, T., Clarke, T., Rouncefield, M.: Probing the Probes. In: Proceedings of the Participatory Design Conference, pp. 23-25 (2002) 
14. Hindus, D., Mainwaring, S.D., Leduc, N., Hagstrom, N.L., Bayley, O.: Casablanca: Designing Social Communication Devices for the Home. In: Proceedings of the CHI'01, pp. 325-332. ACM Press, New York (2001)

15. Hulkko, S., Keinonen, T., Mattelmäki, T., Virtanen, K.: Mobile Probes. In: Proceedings of NordiCHI'04, pp. 43-51 (2004)

16. Hunka, S.: The computer-aided instruction activities of the Division of Educational Research Services at the University of Alberta. International Journal of Man-Machine Studies 5(3), 329-336 (1973)

17. Hutchinson, H., Mackay, W., Westerlund, B., Bederson, B.B., Druin, A., Plaisant, C., Beaudouin-Lafon, M., Conversy, S., Evans, H., Hansen, H., Roussel, N., Eiderbäck, B., Lindquist, S., Sundblad, Y.: Technology Probes: Inspiring Design for and with Families. In: Proceedings of the CHI'03, pp. 17-24. ACM Press, New York (2003)

18. Iversen, O.S., Nielsen, C.: Using Digital Cultural Probes in Design with Children. In: Proceedings Interaction Design \& Children, pp. 154-154. ACM Press, New York (2003)

19. Jääskö, V., Mattelmäki, T.: Observing and Probing. In: Proceedings of the International Conference on Designing Pleasurable Products and Interfaces DPPI'03, pp. 126-131. ACM Press, New York (2003)

20. Juul, J.: Half-Real: Video Games between Real Rules and Fictional Worlds. MIT Press, Cambridge (2006)

21. Muller, M.J.: Participatory design issue. CPSR Newsletter 12(3) (1994), http:// www.cpsr.org/publications/newsletters/issues/1994/Summer1994

22. Muller, M.J.: Participatory design: the third space in HCI. In: Jacko, J.A., Sears, A. (eds.) The human-computer interaction handbook: fundamentals, evolving technologies and emerging applications, pp. 1051-1068. Lawrence Erlbaum Associates, Mahwah

23. Neal, A.S., Simons, R.M.: Playback: A method for evaluating the usability of software and its documentation. In: Proceedings of the CHI'83, pp. 78-82. ACM Press, New York (1983)

24. Nicol, A.: Interface design for hyperdata: Models, maps, and cues. In: Human Factors Society 32nd Annual Meeting, pp. 308-312 (1988)

25. Read, J., MacFarlane, S., Casey, C.: Endurability, Engagement and Expectations: Measuring Children's Fun. In: Proceedings of Interaction Design and Children, pp. 189$198(2002)$

26. Taylor, A.S., Swan, L.: Artful Systems in the Home. In: Proceedings of the Human Factors in Computing Systems Conference (CHI'05), pp. 641-650. ACM Press, Portland (2005)

27. Wyeth, P.: Ethnography in the kindergarten: examining children's play experiences. In: Proceedings CHI'06, pp. 1225-1228. ACM Press, New York (2006) 